\title{
Safety Strategies in Primary Care
}

Patient safety is a young discipline that emerged from medico-legal concerns associated with the risk of occurrence of specific and easily identifiable adverse events that were mostly associated with hospital care. In primary care however patients are managed over long periods of time and the safety issues that arise are likely to be of a very different character. We have earlier suggested that we should recast patient safety as the management of risk over time; this perspective may be better adapted to the longer time scales of primary care.

With the exception of exceptional criminal behaviour, such as the example of Harold Shipman (Baker and Hurwitz 2009), primary care has not been considered as an important source of specific adverse events. The priorities in primary care have been to improve access and overall quality of care, rather than to examine system vulnerabilities and safety issues. However once we begin to examine safety over time, rather than in terms of specific incidents, safety issues may become more visible. In this chapter we briefly outline current knowledge of patient safety in primary care and then consider whether the five strategic approaches can be applied in this context.

\section{Challenges for Primary Care}

Primary care in every country faces huge challenges. People are living longer, often with one or more chronic conditions, and need a greater degree of support in the community while still expecting to have a good quality of life at home. Primary care practitioners are dealing with more patients with complex conditions and comorbidities making it impossible to provide the best and safest care to every patient. Primary care clinics have to coordinate both a very wide range of professions and respond to patient values and preferences. The increasing need to personalise medicine and engage the patient in decisions about their care, while according with the values of primary care, demands more time than is realistically available (Snowdon et al. 2014) 
Primary care physicians express frustration that the knowledge and skills they are expected to master exceed the limits of human capability (Bodenheimer 2006). The introduction of genomics and personalized medicine will only increase the complexity and demands placed on primary care services and the knowledge and technologies that staff need to understand and employ. The number of general practitioners working alone is falling rapidly. Primary care doctors are working in larger clinics and federations to provide a more consistent and coordinated approach to care. Nurses and other professions are taking on increased responsibilities and a wider clinical remit. However these changes, while important, will not be sufficient to address current and future challenges. Safety in primary care needs to be reconsidered in the light of the above, increasing the priority of national primary care patient safety strategies and developing interventions appropriate to the context.

\section{The Nature of Risk in Primary Care}

Doctors in primary care work together to present and solve problems in short consultations, typically 7-16 min across Europe. Patients often (but not invariably) present with early manifestations of illness, often against a backgrounds of preexisting psychosocial problems and physical co-morbidities. Diagnosis in such circumstances is necessarily provisional and general practitioners face an enormously difficult task in identifying the few cases of serious illness amongst the very large number of minor problems. To be 'safe' in this context, in the sense of being certain that a patient does not have a serious illness, is not feasible. To investigate every problem to achieve diagnostic certainty would not be good practice; the anxiety generated, the risks of investigation and tests and the inconvenience to patients would be counter-productive. In addition any healthcare system would be bankrupt within months. Given this equation, time is often used as a diagnostic and therapeutic tool, but always with considerable latitude.

Patients in primary care are much freer than in any hospital system. They may decide not to comply with their nurse or doctor's recommendations because they conflict with personal aims or lifestyle; this is typically the case of 30-50\% of patients (Barber 2002). Patients in primary care, because of their greater autonomy, may increase the risks of adverse events in some circumstances which poses many difficult ethical and medico-legal issues (Buetow et al. 2009).

Until recently many general practitioners worked alone or in small groups. This model of practice, often combined with a very high workload, made it difficult to see risk at a system level or consider broad risk management strategies. General practitioners and other primary care staff may have high personal standards of care without being aware of the frequency or impact of any errors or the vulnerabilities and risks to patients in the wider system of care (Jacobson et al. 2003). The flexibility, diversity and personal approach for every patient that primary care clinicians rightly regard as a strength make it very challenging to define error and adverse events in a reasonable and consistent manner. 


\section{Error and Harm in Primary Care}

Studies in hospitals have shown that different methods of gathering data reveal different types of error and harm and that a combination of methods is needed to map the landscape of safety (Hogan et al. 2008). The same is true in primary care (Sandars and Esmail 2003). One study used five contrasting methods to identify adverse events: physician reported adverse events, pharmacist reported adverse events, patients' experiences of adverse events, assessment of a random sample of medical records, and assessment of all deceased patients. There was almost no overlap of adverse events detected between these methods. The patient survey accounted for the highest number of events and the pharmacist reports for the lowest number (Wetzels et al. 2008). These difficulties in measurement are partly due to the lack of developed systems of monitoring safety in this context but also to the difficulties of definition of both error and adverse events.

The top five medical errors reported by family physicians are: errors in prescribing medications; errors in getting the right laboratory test done for the right patient at the right time; filing system errors; errors in dispensing medications; and errors in responding to abnormal laboratory test results. Poor communication and coordination between professionals and different elements of the health and social care system are the primary cause of many of the problems identified (Dovey et al. 2003). The lack of timely and accurate information after patients are discharged from hospital and delays in obtaining test results are both major risks (Kripalani et al. 2007; Callen et al. 2012). A more recent study of adverse events in primary care (ESPRIT) used a prospective method gathering data over seven consecutive days (Kret and Michel 2013). General practitioners reported 475 errors over a total of 13,438 visits (just under $3 \%$ ) but $95 \%$ of those reported errors were minor and any consequences they had were immediately recognized. These studies identify important problems, but they are restricted to those immediately visible to the primary care doctor, which in effect means those occurring within the clinic or involving communication with other services

Studies which monitor errors within a specific time period, while valuable, will clearly not detect problems that are only revealed in the longer term, such as wrong or delayed diagnosis which are far more prominent in analyses of claims and complaints. The most common allegation in medical negligence claims in primary care by far (up to $40 \%$ of the total claims) is missed or delayed diagnosis especially for cancer and cardiac disease (Gandhi et al. 2006; Singh et al. 2013). This reflects again how difficult it is for general practitioners individually to monitor and detect rare but serious problems that are not immediately apparent in the daily routine and also the need to consider safety issues over much longer time periods in this context

\section{Diagnostic Errors}

Diagnostic errors have not yet received the attention they deserve, considering their probable importance in leading to harm or sub-standard treatment for patients; the 
emphasis on systems has led us away from examining core clinical skills such as diagnosis and decision making (Wachter 2010) but these are now becoming a major focus. Cancer outcomes in the United Kingdom, while improving, are not as good as in many European countries and this may be partly explained by delayed or incorrect initial diagnoses (Lyratzopoulos et al. 2014). Diagnostic errors are difficult to study, being hard to define, hard to specify as occurring at a particular point in time and not directly observable. The term 'diagnostic error' may indicate either a relatively discrete event, such as missing a fracture on an X-ray, or a narrative which unfolds over months or even years, such as a delayed diagnosis of lung cancer because of failures in the coordination of outpatient care (Vincent 2010). These examples show that the term error can be an oversimplification of a long story of undiagnosed illness.

Studies of multiple consultations in the presentation of cancer show that the nature of the disease, both its presentation and rarity, is a powerful predictor of speed of diagnosis. Most patients with cancer present to primary care with symptoms that have low or very low positive predictive values. Even "red flag" symptoms (such as rectal bleeding, dysphagia, haemoptysis, and haematuria) are not strongly associated with the presence of cancer. Despite these challenges about $80 \%$ of patients with cancer are referred to a hospital specialist after one $(50 \%)$ or two $(30 \%)$ consultations. But a substantial minority $(20 \%)$ of patients with cancer visit a primary care doctor with relevant symptoms three or more times before referral. This number is often considered by policy makers and cancer charities to reflect an avoidable delay. These patients however are often those with cancers which are particularly difficult to diagnose because of their non-specific symptom pattern (Lyratzopoulos et al. 2014).

We still have many challenges to address even in providing a complete account of the various errors, adverse events and wider safety issues in primary care. Problems of definition, methodology and method abound. There is however evidence from a number of quarters of risks to patients from vulnerabilities in both individuals and systems, though this realisation must be tempered by the fact that primary care practitioners cannot (and emphatically should not) try to minimise all possible risk; such an approach would lead to massive over-investigation and treatment and would be completely unaffordable. Managing risk in this context is a challenging affair and we would suggest, currently largely conceptualised as the responsibility of individual doctors. Doctors, nurses and other primary care professionals obviously play a critical role in the management of risk in the negotiation, shared decision making and treatment of individual patients. However we need, as in hospitals, to look beyond the individual perspective and try to imagine what managing risk and safety across a population of patients might look like. Can we apply the framework of five strategies and the associated interventions to this context to provide a conceptual and practical approach to risk management in primary care?

\section{Safety as Best Practice}

Adherence to best practice and evidence based medicine is as important in primary care as in other contexts. In England considerable emphasis has been placed on external incentives for improving primary care most notably in the use of 
Payment-for-Performance system (P4P). The United Kingdom pioneered the idea in 2004 with the Quality and Outcomes Framework, and the United States, France and other countries have developed similar schemes. The Idea of P4P is simple enough: pay for compliance to evidence based medicine. Pay for performance can certainly drive change in specific practices but its overall impact on quality of care and professional values is still debated (Lee et al. 2012; Hussey et al. 2011; Ryan et al. 2015). Irrespective of this, the more difficult issue from the safety perspective is that $\mathrm{P} 4 \mathrm{P}$ does not address the three top three adverse events as cited in the literature: delayed and missed diagnosis; medication safety; and poor strategies of care and inadequate surveillance (Brami and Amalberti 2010; Lorincz et al. 2011).

Many interventions use quality improvement approaches to improve adherence to guidelines to improve outcomes for patients (Marshall et al. 2013). For example, depression in primary care settings is often not well managed or treated with resultant poor outcomes. As depression is one of the major causes of disability worldwide this is a critical issue. In a remarkable early study of quality improvement approaches, managed primary care practices in the United States were randomized to usual care or a quality improvement programme. The intervention involved institutional commitment to quality improvement, identification of a pool of potentially depressed patients, training local experts and nurse specialists to provide clinician and patient education, and either nurses for medication follow-up or access to trained psychotherapists. Mental health outcomes and retention of employment of depressed patients improved over a year, while medical visits did not increase overall. A modest investment in quality improvement produced substantial gains in some areas, including a marked increased detection of patients with depression (Wells et al. 2000).

Studies of known diagnostic errors in primary find that most concern common conditions such as pneumonia, cancer, congestive heart failure, acute renal failure, and urinary tract infections; this is of course partly because these conditions are common in any case. Problems identified may lie in the clinical encounter but are also related to referrals, patient-related factors, follow-up and tracking of diagnostic information, and performance and interpretation of diagnostic tests. While some of these problems may be addressed by improving the skills of individual practitioners this is unlikely to have a major impact. To begin with many diagnostic errors may be due to fundamental features of human cognition which are hard to change. People make frequent and effective use of heuristics in day to day thinking which are generally extremely useful but which can also mislead in situations where more analytical thinking is required (Kahneman 2011). Large numbers of heuristics and biases have been identified (Croskerry 2013) and it is not yet clear whether it is possible, still less cost effective, to train people to improve diagnostic accuracy. In terms of the management of risk we may be better to invest in improving the more tractable aspects of the system (such as communication of test results) and, probably even more important, investing more time and effort in following up patients who attend for an initial presentation with potentially serious symptoms. This would require the development of failsafe systems for overlooked abnormal tests and recall of patients who did not attend planned investigations or follow up appointments (Lyratzopoulos et al. 2014). In our terms we would move from a strategy of best practice and system 
improvement towards one of monitoring, adaptation and recovery. We would accept that some diagnostic delays and errors are inevitable and shift the balance of resources towards rapid detection.

\section{Improving the System}

Delivering the care suggested by guidelines is obviously a desirable objective, but the goal will remain difficult to achieve. There are many reasons for this but two are particularly important. First, guidelines are only a partial guide to treatment even for a relatively healthy person with a single condition. When caring for a frail older person with multiple problems doctors need to make many adjustments to achieve the best care for that individual (Persell et al. 2010). A second major problem is the extraordinary pace of medical innovation and the accompanying exponential growth in scientific knowledge in modern medicine; the half-life of knowledge is only 6 years in most specialities (Shojania et al. 2007; Alderson et al. 2014). Once the new knowledge is available, it takes time to consolidate and put it in the form of guidelines and recommendations. It takes as long again to establish a system of new recommendations to work, updated at a proper pace, and with relevant information for ageing comorbid patients.

The introduction of information technology and Electronic Health records represent the best chance of responding to the rapid evolution of medical knowledge and practice. New technologies are expected to assist and support medical decision making and prescribing, provide prompts for ordering and checking test results, enhance cooperation and allow patients to access their medical record (De Lusignan et al. 2014); they may also facilitate new approaches to measuring clinical performance and detecting poor care (Weiner et al. 2012). But the effective use of such technology will depend on consistent deployment at a national level and on associated training in how to use these systems effectively without being burdened by an overload of information, recommendations and alerts (Shoen et al. 2012; Jones et al. 2014). The full benefits of such systems have not yet been realised but we are already beginning to see that their introduction has a number of unanticipated consequences, some of which are highly undesirable. For instance clinicians in the past would go to speak to a radiologist to discuss an ambiguous CT scan, whereas now they will make their own solitary decision from a screen. Young doctors will review their patients on the electronic health record rather than actually go and see them (Wachter 2015).

Optimisation strategies (best practice and improving the system) are perfectly feasible when conducted at scale but much more difficult to implement in a small primary care clinic or practice. The improvements needed in the primary care system and the levers of change are national or at least regional issues. Programmes with clear and specific improvement targets can have an impact, as the example of treatment of depression shows, but considerable resources are needed to have an impact at scale. Primary care clinics can make some use of 
optimisation strategies but, at a local level, may need to make more use of the other forms of safety strategy which place a stronger emphasis on the active management of risk.

\section{Risk Control Strategies}

When systems are under pressure risk control strategies need to be considered to maintain safety and potentially also to constrain costs. An important example of risk control is the deliberate restriction of clinical practice in circumstances posing high risk to patients. This method of controlling risk is most prominent in the prescription and administration of high risk medication. For instance, in primary care certain drugs cannot be prescribed by general practitioners or supplied by community pharmacists.

The argument for risk control is essentially that it is better to explicitly manage demand and conditions of work in order to maintain standards and preserve safety; the alternative is a system which delivers some high quality care but which potentially runs out of control. The most obvious potential control is to cap the maximum number of patients who are under the care of a single primary care team, which varies according to patient characteristics and how care is provided. Provided some realistic assessment of patient need and consultation length can be made, then capping the number of patients per team is a possible option but solutions of this kind can only be achieved at a national level. Demand can be managed locally by greater involvement of nurses and paramedical staff in care delivery or by transfer to hospitals or other facilities but this may not be feasible in isolated or poorer areas. There are however many examples of risk control in primary care and the potential for a much more thorough consideration of this particular strategy.

\section{Control by Assessment of Competency}

Almost all countries with developed healthcare systems have procedures for licensing doctors, identifying and potentially retraining those who fall below the required standard. Whatever the merits of the a systems approach to safety, there is no doubt that a proportion of problems are linked to the standard of care provided by individuals; in Australia for instance $3 \%$ of the workforce accounted for half the complaints made with some individuals the subject of repeated complaints. Many countries require general practitioners to engage in a CPD or CPE programme (Continuous Professional Development/Education) and a formal re-accreditation process (e.g., Netherlands, Norway, US). Each doctor must demonstrate continuing education and development and compliance with the requirements of the recertification process (Murgatroyd 2011). Poorly performing physicians identified by these systems are retrained with potential restriction on their licence. These surveillance systems however are complex and not always very effective (Lipner et al. 2013). Accountability and sanctions, while a critical part of the safety armament, are not simple to implement or sustain. 


\section{Control of Hazards}

The control of known hazards may have more immediate application in primary care. For example, the use of risk control is very important in mental health. It is perhaps unfortunate that the most immediate examples are those which restrain or control people; locked wards, restraint techniques and pharmaceutical control of people are thankfully much more sparingly than in the past. There are however much more subtle methods of risk control that can be applied at a population level and which attempt to control hazards rather than people. For instance the analgesic paracetamol was a common method of suicide and non-fatal self-harm, responsible for many accidental deaths and a frequently cause of hepatotoxicity and liver unit admissions. Legislation introduced by the United Kingdom government in 1998 restricted the pack size to 32 tablets in pharmacies and 16 tablets for non-pharmacy sales. Reducing packet size sounds an implausible approach to reducing the risk of poisoning but many people interviewed after overdoses reported that it was an impulsive act involving the use of available drugs stored in the home. Impulsive acts therefore became less dangerous with smaller packets. Ten years after the changes there had been a significant and sustained reduction in suicide and harm from paracetamol and a similar successful restriction on other paracetomol based products (Box 9.1) (Gunnell et al. 2008; Hawton et al. 2012).

\section{Box 9.1. Withdrawal of Co-proxamol to Reduce Suicide}

The extent of fatal poisoning with the analgesic co-proxamol was a concern for many years. The margin between therapeutic and potentially lethal concentrations is relatively narrow. Between 1997 and 1999 co-proxamol was the single drug used most frequently for suicide in England and Wales (766 deaths over the 3 year period). The Committee on Safety of Medicines (CSM) advised that co-proxamol should be withdrawn from use in the UK which took place in December 2007.

A steep reduction in prescribing of co-proxamol occurred in the postintervention period $2005-7$ with the number of prescriptions falling by $59 \%$. Prescribing of some other analgesics increased significantly during this time. These changes were associated with a major reduction in deaths involving coproxamol compared with an estimated 295 fewer suicides and 349 fewer deaths including accidental poisonings. During the 6 years following the withdrawal of co-proxamol there was a major reduction in poisoning deaths involving this drug without apparent increase in deaths involving other analgesics.

Adapted from Hawton et al. (2012)

\section{Monitoring, Adaptation and Response}

General practitioners and other primary care professionals are of course constantly engaged in monitoring patients but a safety strategy of this nature represents a broader attempt to enhance the capacity to detect deterioration and other problems 
in the delivery of healthcare to the wider population. As examples we consider one proposal targeted at professionals and a second one aimed at developing a more collaborative culture to help primary care professionals adopt a more patient centred approach and enhance teamwork.

\section{Developing a More Systematic Approach to Watching and Waiting}

Time is an essential means of managing risk in primary care. A general practitioner may know from the presenting symptoms that there is a small chance that this is a cancer or other serious complaint; but to refer everyone with such symptoms is neither feasible nor good practice. Instead, they ask the patient to watch and to monitor any change. The use of time is central to the doctor's routines and practice management. Over time diseases and circumstances evolve and a problem encountered at one time will not be the same at a later point. Taking more time solves many health problems in general practice; some will simply resolve, regardless of the diagnosis or intervention, while others will manifest a much clearer symptom pattern. In a significant number of cases, the best way to deal with a situation is just to monitor its development and refrain from clinical intervention. Waiting is paradoxically often more valuable than acting immediately, provided both patient and doctor collaborate in the monitoring of symptoms and trust is maintained on either side. While this strategy is well known and implicitly accepted by both doctors and patients the use of time as a strategy for management has seldom been explicitly studied.

The development of the Tempos Framework (Amalberti and Brami 2012) reflects the importance of time management in primary care. Five time scales termed 'Tempos' requiring parallel processing by GPs are distinguished in the framework: (1) disease's Tempo (unexpected rapid evolutions, slow reaction to treatment); (2) office's Tempo (day-to-day agenda and interruptions); (3) patient's Tempo (time to express symptoms, compliance, emotion); (4) system's Tempo (time for appointments, exams, and feedback) and (5) physician's Tempo (time to access knowledge). This framework (Table 9.1) may serve as a basis for detecting adverse events and recovery, as well as improving adverse event analysis (see Chap. 6).

\section{Improving Transitions Between Hospital and Primary Care}

Although the attempt to improve transitions of care has been largely driven from the hospital side it has important implications for safety in primary care. Unintentional changes to medication regimens are an important and well-studied hazard; patients may be discharged from hospital on a very different set of medications from their pre-admission medications, not because of clinical need but through failure to reassess medication at the time of discharge. Medication reconciliation is a process, usually carried out by pharmacists, in which a full assessment is made of the patient's medication before hospital and the new medicines prescribed in hospital, 
Table 9.1 Tempo framework for primary care

\begin{tabular}{l|l}
\hline \multirow{2}{*}{$\begin{array}{l}\text { Disease's } \\
\text { tempo }\end{array}$} & Misleading pathology evolving moving faster or slower than is typical \\
\cline { 2 - 2 } & $\begin{array}{l}\text { Inappropriate therapeutic action, too slow, not efficient. Unfounded } \\
\text { reassurance given to the patient on the basis of standard evolution }\end{array}$ \\
\cline { 2 - 2 } & $\begin{array}{l}\text { Poor explanations/instructions given to the patient and relatives on what } \\
\text { should occur, when, what makes an alerting pattern, and what to do. }\end{array}$ \\
\hline $\begin{array}{l}\text { Doctor's } \\
\text { Tempo }\end{array}$ & $\begin{array}{l}\text { Experiencing difficulties in accessing the right knowledge at the right time, } \\
\text { due to misleading symptoms, fatigue, pressure or interruptions. }\end{array}$ \\
\cline { 2 - 2 } & $\begin{array}{l}\text { Technique required for clinical intervention not applied with all usual rigor, } \\
\text { due to poor practice, interruptions, fatigue, and more }\end{array}$ \\
\cline { 2 - 2 } & Medical case not detected as going beyond doctor's competence \\
\hline \multirow{2}{*}{$\begin{array}{l}\text { Office's } \\
\text { tempo }\end{array}$} & Excessive busy diaries, time pressure \\
\cline { 2 - 2 } & Interruptions managements, telephone, patients, secretary, and more \\
\cline { 2 - 2 } & $\begin{array}{l}\text { Incomplete traceability of medical data, rushed medical history, writing style } \\
\text { limited to minimum }\end{array}$ \\
\hline Patient's \\
tempo & Failure to reveal symptoms, minimizing, or postponing the expression \\
\cline { 2 - 2 } $\begin{array}{l}\text { System's } \\
\text { tempo }\end{array}$ & Poor doctor-patient relationship, conflicts, specific contexts \\
\cline { 2 - 2 } & Delay in getting appointments for examinations (imagery) or with specialists \\
\cline { 2 - 2 } & Lost information among careers, lost mail, lost message \\
\hline
\end{tabular}

Adapted from Amalberti and Brami (2012)

to ensure the patient returns home with the correct medication. Medication reconciliation alone, although important, has not been shown to have clinically significant outcomes, such as reducing subsequent hospitalisation (Kwan et al. 2013). Attention has now turned to a fuller assessment of the entire transition process driven by the high rate of early readmission after discharge. In the United States for instance, nearly one in five Medicare patients are readmitted within 30 days of discharge (Rennke et al. 2013).

Programmes to improve transition have a variety of components and there is as yet little consistency of approach in the various programmes studied. Most have a dedicated discharge team, carry out medication reconciliation, and provide guidance and sometimes training to the patient and family. Some however also extend to a dedicated transition nurse or other professional who has the specific responsibility of monitoring the patient's progress after discharge through telephone calls or visits, coordinating other professionals and responding to any signs of deterioration. Studies give few details of how these programmes are funded and how much training is needed for such people. Strikingly, even the most comprehensive programmes made little if any attempt to engage the main primary care providers (Rennke et al. 2013). This broad approach relies partly on improving the reliability of care within the hospital but, from our point of view, the approach after discharge is one of anticipating, monitoring, adapting and responding to patient need; this is a very different safety strategy than often considered in the primary care context which is largely dominated by attempts to improve adherence to guidelines.

Strategies to improve safety in primary care will require many of the components of these transition programmes. A strong emphasis on patient engagement, 
coordination and cooperation both within and between teams and above all a mindset of anticipation, monitoring and caring for the patient beyond their immediate hospital stay or primary care encounter. Primary care providers do of course take this view but current systems, or rather lack of systems, make it very difficult to achieve in practice. New roles in the team could be devoted to this coordination and organisation. New posts of practice facilitators and care managers would enhance the capacity of the primary care team to monitor safety. The care manager's central role could deliver and coordinate services for patients, including coordinating care across clinicians, settings, and conditions, and helping patients access and navigate the system (Taylor et al. 2013).

\section{Mitigation}

The capacity to respond rapidly to deterioration is critical to safe care both within hospital and outside, as we have discussed above. The term mitigation extends to the care of patients whose care has failed them in some way leading to harm that has become a new problem in its own right, both for the patient and those caring for them. Dealing with such scenarios of course requires the capacity for rapid response and for all the necessary clinical interventions, but also requires a broader response to deal with the specific problems associated with harm due to poor care rather than to disease.

In other settings we have emphasised the need for support for both patients and staff and this is equally true in primary care. Developing formal programmes to provide such support has been a struggle in hospitals which have the resources and scale to initiate and sustain such help. In primary care, support for either patients or staff relies on the actions of individuals and on responsive and compassionate colleagues. In most cases this is all that is needed but, as we have argued earlier, more extensive and longer term counselling or other interventions may be needed to help patients, careers or staff who have been involved in a serious error or failure. This is currently very difficult to provide in primary care, though some help is given from professional associations. As further integration takes place in primary care we will be able to think more strategically about the management of risk in populations of people and, while prevention and detection will be to the fore, the mitigation of harm should not be neglected.

\section{Reflections on Safety in Primary Care}

It may seem premature to think about safety strategies in primary care given the slow pace of development of patient safety in this setting. A review of safety in primary care in the United States published 10 years after the landmark report 'To err is human' found numerous major gaps in understanding of ambulatory safety and almost no credible studies on how to improve primary care safety (Lorincz et al. 2011). There is still a need for basic epidemiological data, for more analyses of the causes of harm to patients in primary care and for the development of specific 
interventions (Wynia and Classen 2011). We would add that the very concept of patient safety in primary care needs to be examined as, in its current form, it may not resonate sufficiently with primary care practitioners. For patients, safety in primary care is partly associated with control and regulation but strongly linked with personal trust and relationships (Rhodes et al. 2015).

We believe nevertheless that sketching the kind of strategies that might be employed and drawing on a conceptual framework will assist both our understanding of safety in primary care and the development of appropriate intervention strategies. Innovations in information technology will potentially have a massive impact on the coordination of care and the monitoring and support of patients in their homes. Improving systems within practices and clinics and adherence to clinical guidelines are important but may have less impact than in the more structured environment of hospitals. Risk control, in the sense of restricting demand and being clear about competencies and standards, needs to be examined as a formal overall strategy not just in the context of specific clinical issues.

Primary care however is, par excellence, an adaptive system in which clinical decisions evolve from highly individual clinical encounters and relationships in which patient values and preferences are often the pre-eminent consideration. In such contexts we believe that the development of sophisticated monitoring and response strategies may be more important in the overall balance than any of the other broad approaches. The full engagement and indeed education and training of patients and careers in the management of risk will be a necessary core of any such approach. It may be that risk will be more effectively managed in a loose system which incorporates rapid adaptation and response than by the imposition of guidelines and controls. This view however is, as yet, just a view and requires exploration, development and testing.

\section{Key Points}

- Primary care faces huge challenges. Primary care practitioners are dealing with increasingly complex conditions making it impossible to provide the best and safest care to every patient.

- Primary care staff can have high personal standards of care without being fully aware of the risks to patients in the wider system of care. This makes it difficult to understand risk at a system level or consider population oriented risk management strategies.

- The concept of patient safety in its current form it may not resonate sufficiently with primary care practitioners. For patients, safety in primary care is strongly linked with personal trust and relationships

- Poor communication and coordination between different elements of the health and social care system, the lack of timely and accurate information after patients are discharged from hospital and delays in obtaining test results are major risks. 
- Diagnostic errors have not yet received the attention they deserve, considering their probable importance in leading to harm or sub-standard treatment for patients.

- Quality improvement approaches can be used to improve adherence to guidelines to improve outcomes for patients.

- The exponential growth in scientific knowledge is a particular challenge in primary care. New technologies are expected to assist and support medical decision making and prescribing, ordering and checking test results, and enhance cooperation and coordination

- When systems are under pressure risk control strategies need to be considered to maintain safety and potentially also to constrain costs.

- Time, in the sense of intelligent and active watching and waiting, is an essential means of managing risk in primary care.

- Strategies to improve safety in primary care will require a strong emphasis on patient engagement, coordination between teams and a mind-set of anticipation, monitoring and caring for the patient beyond their immediate primary care encounter.

- Risk in primary care may be more effectively managed in a loose system which incorporates rapid adaptation and response than by the imposition of guidelines and controls.

Open Access This chapter is distributed under the terms of the Creative Commons Attribution Noncommercial License, which permits any noncommercial use, distribution, and reproduction in any medium, provided the original author(s) and source are credited.

\section{References}

Alderson L, Alderson P, Tan T (2014) Median life span of a cohort of national institute for health and care excellence clinical guidelines was about 60 months. J Clin Epidemiol 67(1):52-55

Amalberti R, Brami J (2012) 'Tempos' management in primary care: a key factor for classifying adverse events, and improving quality and safety. BMJ Qual Saf 21:729-736

Baker R, Hurwitz B (2009) Intentionally harmful violations and patient safety: the example of Harold Shipman. J Royal Soc Med 102:223-227

Barber N (2002) Should we consider non-compliance a medical error? Qual Saf Health Care 11(1):81-84

Bodenheimer T (2006) Primary care: will it survive? New Eng J Med 335(9):861-862

Brami J, Amalberti R (2010) La sécurité du patient en médecine générale. Springer

Buetow S, Kiata L, Liew T, Kenealy T, Dovey S, Elwyn G (2009) Patient error: a preliminary taxonomy. Ann Fam Med 7:223-231

Callen JL, Westbrook JI, Georgiou A, Li J (2012) Failure to follow-up test results for ambulatory patients: a systematic review. J Gen Intern Med 27(10):1334-1348

Croskerry P (2013) From mindless to mindful practice-cognitive bias and clinical decision making. New Eng J Med 368(26):2445-2448 
De Lusignan S, Mold F, Sheikh A, Majeed A, Wyatt J, Quinn T, Cavill M et al (2014) Patients' online access to their electronic health records and linked online services: a systematic interpretative review. BMJ Open 4:e006021

Dovey SM, Phillips RL, Green LA, Fryer GE (2003) Types of medical errors commonly reported by family physicians. Am Fam Physician 67(4):697

Gandhi TK, Kachalia A, Thomas EJ, Puopolo AL, Yoon C, Brennan TA, Studdert DM (2006) Missed and delayed diagnoses in the ambulatory setting: a study of closed malpractice claims. Ann Intern Med 145(7):488-496

Gunnell D, Hawton K, Ho D, Evans J, O’Connor S, Potokar J, Donovan J, Kapur N (2008) Hospital admissions for self-harm after discharge from psychiatric inpatient care: cohort study. BMJ 337:a2278

Hawton K, Betgen H, Simkin S, Wells C, Kapur N, Gunnell D (2012) Six-year follow-up of impact of co-proxamol withdrawal in England and Wales on prescribing and deaths: time-series study. PLoS Med 9(5):606

Hogan H, Olsen S, Scobie S, Chapman E, Sachs R, McKee M, Vincent C, Thomson R (2008) What can we learn about patient safety from information sources within an acute hospital: a step on the ladder of integrated risk management? Qual Saf Health Care 17(3):209-215. doi:10.1136/ qshc. 2006.020008

Hussey PS, Ridgely MS, Rosenthal MB (2011) The PROMETHEUS bundled payment experiment: slow start shows problems in implementing new payment models. Health Aff 30(11): 2116-2124

Jacobson L, Elwyn G, Robling M, Jones RT (2003) Error and safety in primary care: no clear boundaries. Fam Pract 20(3):237-241

Jones S, Rudin R, Perry T, Shekelle P (2014) Health information technology: an updated systematic review with a focus on meaningful use. Ann Intern Med 160:48-54

Kahneman D (2011) Thinking, fast and slow. Macmillan, New York

Kret M, Michel P (2013) Esprit, Etude Nationale en Soins primaires sur les événements indésirables, Rapport CCECQA. http://www.ccecqa.asso.fr/projets/esprit

Kripalani S, LeFevre F, Phillips CO, Williams MV, Basaviah P, Baker DW (2007) Deficits in communication and information transfer between hospital-based and primary care physicians: implications for patient safety and continuity of care. JAMA 297(8):831-841

Kwan JL, Lo L, Sampson M, Shojania KG (2013) Medication reconciliation during transitions of care as a patient safety strategy. A systematic review. Ann Intern Med 158(5_Part_2):397-403. doi:10.7326/0003-4819-158-5-201303051-00006

Lee G, Kleinman K, Soumerai S, Tse A, Cole D, Fridkin S, Horan T, Platt R, Gay C, Kassler W, Goldmann D, John Jernigan J, Ashish K, Jha A (2012) Effect of non-payment for preventable infections in U.S. Hospitals. New Engl J Med 367:1428-1437

Lipner RS, Hess BJ, Phillips RL Jr (2013) Specialty board certification in the United States: issues and evidence. J Continu Edu Health Prof 33(Suppl 1):S20-S35

Lorincz CY, Drazen E, Sokol PE (2011) Research in ambulatory patient safety 2000-2010: a 10-year review. American Medical Association, Chicago

Lyratzopoulos G, Wardle J, Rubin G (2014) Rethinking diagnostic delay in cancer: how difficult is the diagnosis? BMJ 349:g7400

Marshall M, Pronovost P, Dixon-Woods M (2013) Promotion of improvement as a science. Lancet 381(9864):419-421

Murgatroyd G (2011) Continuing professional development. General Medical Council, London

Persell S, Dolan N, Friesema E, Thompson J, Kaiser D, Baker D (2010) Frequency of inappropriate medical exceptions to quality measures. Ann Intern Med 152:225-231

Rennke S, Nguyen OK, Shoeb MH, Magan Y, Wachter RM, Ranji SR (2013) Hospital-initiated transitional care interventions as a patient safety strategy. A systematic review. Ann Intern Med 158(5_Part_2):433-440

Rhodes P, Campbell S, Sanders C (2015) Trust, temporality and systems: how do patients understand patient safety in primary care? A qualitative study. Health Expect. doi:10.1111/hex.12342 
Ryan AM, Burgess JF, Pesko MF, Borden WB, Dimick JB (2015) The early effects of medicare's mandatory hospital Pay-for-performance program. Health Serv Res 50(1):81-97

Sandars J, Esmail A (2003) The frequency and nature of medical error in primary care: understanding the diversity across studies. Fam Pract 20(3):231-236

Singh H, Giardina T, Meyer A, Forjuoh S, Reis M, Thomas EJ (2013) Types and origins of diagnostic errors in primary care settings. JAMA Inter Med 173:18-25

Shoen C, Osborn R, Squires D, Pasmussen P, Pierson R, Appelbaum S (2012) A survey of primary care doctors in ten countries shows progress in use of health information technology, less in other areas. Health Aff 31(12):2805-2816

Shojania K, Sampson M, Ansari M, JI S, Douvette S, Moher D (2007) How quickly do systematic reviews go out of date? (2007). A survival analysis. Ann Inter Med 147:224-233

Snowdon A, Scnarr K, Alessi C (2014) It's all about me, the personalization of health system. Western University Canada, London

Taylor E, Matcha R, Meyers D, Genevro J, Peikes D (2013) Enhancing the primary care team to provide redesigned care: the roles of practice facilitators and care managers. Ann Inter Med $1: 80-83$

Vincent C (2010) Patient safety, 2nd edn. Wiley Blackwell, Oxford

Wetzels R, Wolters R, van Weel C, Wensing M (2008) Mix of methods is needed to identify adverse events in general practice: a prospective observational study. BMC Fam Pract 15(9):35

Wachter RM (2010) Why diagnostic errors don't get any respect-and what can be done about them. Health Aff 29(9):1605-1610

Wachter RM (2015) The digital doctor. McGraw Hill, New York

Weiner JP, Fowles JB, Chan KS (2012) New paradigms for measuring clinical performance using electronic health records. International J Qual Health Care 24(3):200-205

Wells KB, Sherbourne C, Schoenbaum M et al (2000) Impact of disseminating quality improvement programs for depression in managed primary care: a randomized controlled trial. JAMA 283(2):212-220. doi:10.1001/jama.283.2.212

Wynia MK, Classen DC (2011) Improving ambulatory patient safety. JAMA 306(22):2504-2505. doi:10.1001/jama.2011.1820 